\title{
Outcomes of Tracheostomized Subjects Undergoing Prolonged Mechanical Ventilation in an Intermediate-Care Facility
}

\author{
Bertrand Herer MD
}

\begin{abstract}
BACKGROUND: The incidence of chronically ill subjects with prolonged mechanical ventilation (PMV) has significantly increased over the last decade because of improvements in acute critical care. The aim of this study was to describe the outcomes and care pathways of subjects receiving PMV through a tracheostomy tube in an intermediate-care facility. METHODS: Sixty-six subjects with chronic respiratory failure who experienced 109 hospitalizations between December 2010 and December 2012 in a 34-bed post-care unit were retrospectively included and followed for at least $1 \mathrm{y}$. RESULTS: The median (interquartile range [IQR]) length of stay (LOS) was 42 (26-77) d.

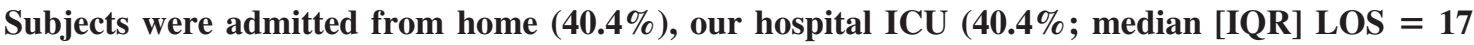
[7-38] d), or another hospital (19.2\%; median [IQR] LOS $=60$ [8-71] d, $P=.001$ vs LOS in ICU). Thirty-five percent of subjects were readmitted at least once during the follow-up period. Sixteen subjects died in the intermediate-care facility. Discharge destinations of alive subjects were home $(n=78)$, another hospital $(n=6)$, a skilled-nursing facility $(n=5)$, or an ICU $(n=4)$. A complete or partial weaning was obtained in $30.3 \%$ of subjects. One year after the first day of hospitalization, $57 \%$ of subjects were alive. CONCLUSIONS: Despite the chance of survival at $1 \mathrm{y}$ and/or weaning from ventilation, the resources needed by subjects with PMV are high, as shown by the number of readmissions and long LOS in our unit and in other hospital units before transfer. Key words: Chronic respiratory failure; health outcomes; intermediate care facility; subject-centered outcomes; prolonged mechanical ventilation; tracheostomy. [Respir Care 2018;63(3):282-288. () 2018 Daedalus Enterprises]
\end{abstract}

\section{Introduction}

Progress in medical care has contributed to an increasing number of patients becoming dependent on long-term ventilation. ${ }^{1,2} \mathrm{Up}$ to $10 \%$ of ventilated patients requiring at least $3 \mathrm{~d}$ of mechanical ventilation will eventually require tracheostomy for prolonged mechanical ventilation (PMV). ${ }^{3}$ As ventilatory assistance is rarely provided in the conventional hospital ward, admission to an ICU is often prolonged in these patients, resulting in ethical and economic concerns. ${ }^{4}$ Respiratory ICUs have been implemented in the United States and in Europe 5,6 to fill the gap between the ICU and the respiratory ward to decrease medical costs, free up ICU beds,

Dr Herer is affiliated with the Centre Hospitalier de Bligny, Briis-SousForges, France.

Correspondence: Bertrand Herer MD, Centre Hospitalier de Bligny, F-91640 Briis-Sous-Forges, France. E-mail: b.herer@ chbligny.fr.

DOI: $10.4187 /$ respcare. 05602 and initiate patient rehabilitation for functional restoration. ${ }^{7,8}$ Important benefits may be expected from this care pathway in terms of costs, staff management, and better use of ICU beds through the admission of patients in real need of intensive care. ${ }^{2,9}$ However, in France, there is a shortage of such units, ${ }^{10}$ and the management of PMV patients is often performed in intermediate-care facilities, to improve patient autonomy, recover sufficient physical condition before returning home, or, in selected cases, to provide assistance in mechanical ventilation weaning.

Few data are available on morbidity and mortality outcomes in subjects with PMV outside the ICU.4,5 However, such data may allow a better understanding of these patients, because their number is likely to increase as a result of an improvement in acute-care management and supportive care in critically ill patients. ${ }^{11}$ The aim of this study was to describe the outcomes and care pathways of consecutive subjects with PMV admitted in an intermediate-care facility in a tertiary care hospital in Ille-de-France, which is the most populated region in France. 


\section{Methods}

\section{Subject Population}

The Bligny Hospital Center is a 363-bed hospital offering acute-care and rehabilitation units for subjects with respiratory, cardiac, diabetic, and oncological diseases. The 34-bed intermediate-care facility is located in the respiratory department and admits yearly about 260 patients. About $50 \%$ of beds are assigned to patients who have been previously treated in ICUs, respiratory high-dependence care units, ${ }^{6,7}$ or general respiratory wards for acute respiratory failure occurring during chronic respiratory failure (CRF). The intermediate-care facility has a $90 \%$ occupancy rate. All of the patients recovered from acute-on-chronic respiratory failure and received comprehensive management, including invasive and noninvasive ventilation, oxygen therapy, and rehabilitation. All patients eligible for inclusion had previously been tracheostomized in the ICU or respiratory ICU and were transferred to our intermediatecare facility with the tracheostomy tube maintained in place. Beds in the intermediate-care facility were fully equipped for invasive ventilation for the management of patients requiring invasive PMV through the tracheostomy tube (19\% of the activity of the unit during the follow-up: December 1, 2010, to December 1, 2012).

Patients were eligible for inclusion in this retrospective study if they had a tracheostomy tube in place for $>7 \mathrm{~d}$ and were clinically stable when the decision was made to transfer them from the ICU or an external hospital to the intermediate-care facility. They were excluded from the study if an end-of-life decision had previously been made. The intermediate-care facility staff consisted of 4 physicians and 2 physical therapists. The nurse/patient ratio during the day shift was 1:8.The following data were recorded for all subjects: demographic features (age, sex, body mass index, Charlson comorbidity score, and smoking history [pack-years]); the referral source (ie, home, ICU, or acute-care hospital); the length of stay (LOS) in ICU or acute-care hospital before admission to our unit (pre-intermediate-care facility LOS) and the LOS in our unit (intermediate-care facility LOS); the discharge destination (home, ICU or acute-care hospital readmission, skilled-nursing facility, or death); and arterial blood gases and vital laboratory data upon admission. No subject had hemodialysis during the intermediate-care facility stay.

All subjects presented with CRF whose cause was classified into 3 categories according to the Eurovent survey ${ }^{12}$ : (1) lung and airway diseases (COPD, cystic fibrosis, bronchiectasis, and pulmonary fibrosis); (2) rib-cage abnormalities (kyphoscoliosis, tuberculosis sequelae such as thoracoplasty, obesity hypoventilation syndrome, and sequelae of lung resection); and (3) neuromuscular diseases (mus-

\section{QUICK LOOK}

\section{Current knowledge}

The incidence of chronically ill patients with prolonged mechanical ventilation (PMV) has significantly increased over the last decade because of improvements in acute critical care. Few data are available on morbidity and mortality outcomes in subjects with PMV outside the ICU.

\section{What this paper contributes to our knowledge}

In subjects who received PMV and were followed for $2 \mathrm{y}$, outcomes were satisfactory in terms of 1-y survival and/or weaning from ventilation, at the expense of a high consumption of resources, as shown by the long stay in our intermediate-care facility and in other hospital units before transfer and by the high readmission rate.

cular dystrophy, motor neuron disease, post-polio kyphoscoliosis, central hypoventilation, spinal cord damage, and phrenic nerve paralysis).

A weaning procedure was initiated as soon as the respiratory status was stabilized after admission to the intermediate-care facility. ${ }^{10}$ Iterative spontaneous breathing trials with gradual reduction of mandatory ventilation over time were performed. Supplemental oxygen administration using a tracheal cannula, breathing exercises, and pulmonary rehabilitation were adapted to subject status with continuous clinical and oximetry monitoring, aiming at repeatedly obtaining reference arterial gasometry data recorded before the acute respiratory episode. Decannulation was considered when subjects tolerated increasing tracheostomy tube capping for up to $24 \mathrm{~h}$ and was performed after a thorough evaluation, including overnight oximetry and tracheal endoscopy.

The primary outcome was the number of weaned subjects. Weaning outcome was classified as follows: $1=$ weaned, no ventilator, decannulated; 2 = weaned, no ventilator, tracheostomy maintained; $3=$ ventilator-dependent with tracheostomy, part-time mechanical ventilation; $4=$ ventilator-dependent with tracheostomy, full-time mechanical ventilation. Secondary outcomes were LOS in the pre-intermediate-care and intermediate-care facilities and survival from the day of admission to the intermediatecare facility and post-intermediate-care facility discharge. All intermediate-care facility survivors or their closest relatives were contacted by telephone in March 2014 for a post-discharge survival evaluation as part of the follow-up. The number $(\%)$ of subjects lost to follow-up was $5(5.8 \%)$ : 4 subjects could not be contacted, and 1 had moved to another address. The conduct of the study was approved by the ethics committee of Bligny Hospital, and informed consent was obtained for all subjects. 


\section{INTERMEDIATE-CARE FACILITY FOR PMV}

Table 1. Demographic, Anthropometric, and Clinical Characteristics of Subjects

\begin{tabular}{|c|c|c|c|c|}
\hline \multirow[b]{2}{*}{ Characteristics } & \multicolumn{4}{|c|}{ Main Cause of CRF } \\
\hline & $\begin{array}{l}\text { Overall Population } \\
\qquad(N=66)\end{array}$ & $\begin{array}{l}\text { Lung and Airway } \\
\text { Diseases }(n=31)\end{array}$ & $\begin{array}{l}\text { Rib-Cage } \\
\text { Abnormalities } \\
(n=25)\end{array}$ & $\begin{array}{l}\text { Neuromuscular } \\
\text { Diseases } \\
(n=10)\end{array}$ \\
\hline Age, mean \pm SD y & $70.41 \pm 9.9$ & $70.30 \pm 9.31$ & $71.72 \pm 9.19$ & $68.30 \pm 13.97$ \\
\hline Male/female, $n$ & $39 / 27$ & $23 / 8$ & $11 / 14$ & $5 / 5$ \\
\hline Smoking history, mean \pm SD pack-years & $26.29 \pm 30.46$ & $40.80 \pm 30.98^{*}$ & $18.40 \pm 27.18$ & $2.50 \pm 5.40$ \\
\hline Body mass index, mean $\pm \mathrm{SD} \mathrm{kg} / \mathrm{m}^{2}$ & $22.60 \pm 7.90$ & $22.90 \pm 6.04$ & $23.30 \pm 9.54$ & $28.77 \pm 8.06$ \\
\hline Cardiovascular comorbidity, $n$ & 14 & 6 & 7 & 1 \\
\hline Previously diagnosed OSA, $n$ & 9 & 3 & 5 & 1 \\
\hline Albumin, mean $\pm \mathrm{SD} g / \mathrm{L}$ & $30.59 \pm 5.85$ & $30.67 \pm 5.62$ & $30.45 \pm 6.06$ & $30.67 \pm 6.75$ \\
\hline Blood urea nitrogen, mean $\pm \mathrm{SD} \mathrm{mg} / \mathrm{L}$ & $7.77 \pm 3.39$ & $7.98 \pm 3.95$ & $7.92 \pm 3.03$ & $6.71 \pm 2.21$ \\
\hline Creatinin, mean $\pm \mathrm{SD}$ mg/L & $79.00 \pm 35.73$ & $84.06 \pm 41.26$ & $77.56 \pm 32.38$ & $66.90 \pm 22.20$ \\
\hline Hematocrit, mean $\pm \mathrm{SD} \%$ & $35.21 \pm 3.89$ & $34.85 \pm 3.08$ & $35.14 \pm 4.75$ & $36.51 \pm 3.88$ \\
\hline Charlson score, mean $\pm \mathrm{SD}$ & $5.56 \pm 1.98$ & $5.81 \pm 2.30$ & $5.36 \pm 1.59$ & $5.30 \pm 1.89$ \\
\hline $\mathrm{P}_{\mathrm{aO}_{2}} / \mathrm{F}_{\mathrm{IO}_{2}}$, mean $\pm \mathrm{SD}$ mm & $313.50 \pm 94.76$ & $313.42 \pm 95.38$ & $316.40 \pm 95.29$ & $306.50 \pm 101.21$ \\
\hline $\mathrm{P}_{\mathrm{aCO}_{2}}$, mean $\pm \mathrm{SD} \mathrm{mmHg}$ & $52.43 \pm 13.75$ & $52.45 \pm 14.98$ & $53.68 \pm 12.80$ & $48.89 \pm 12.72$ \\
\hline $\mathrm{pH}$, mean $\pm \mathrm{SD}$ & $7.38 \pm 0.06$ & $7.37 \pm 0.07$ & $7.39 \pm 0.06$ & $7.39 \pm 0.06$ \\
\hline $\begin{array}{l}* P<.001 \text { when compared with other chronic respirat } \\
\mathrm{CRF}=\text { chronic respiratory failure } \\
\mathrm{OSA}=\text { obstructive sleep apnea }\end{array}$ & groups. & & & \\
\hline
\end{tabular}

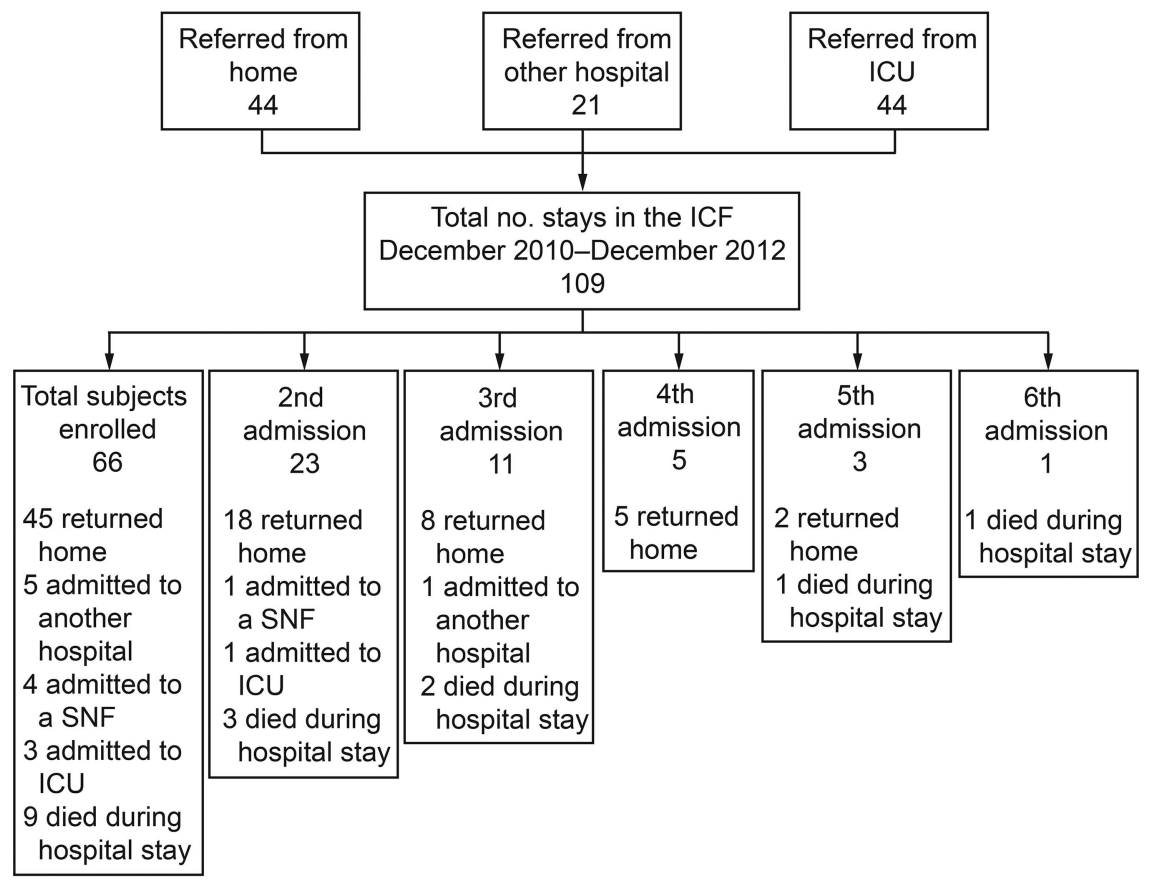

Fig. 1. Flow chart. ICF $=$ intermediate-care facility, SNF = skilled-nursing facility.

\section{Statistical Analysis}

Quantitative data are presented as mean \pm SD or mean with CI. Categorical data are presented as $n(\%)$. LOS data were not normally distributed (Kolmogorov-Smirnov test, $P<.01)$ and are therefore presented as median (interquartile range $[\mathrm{IQR}]$ ). Unpaired $t$ test and correlation coefficient were used for quantitative variables. Chi-square statistics were used for categorical variables. The Kaplan-Meier method was used to describe survival. Survival rate was calculated setting the zero time on the day of admission to the intermediate-care facility 
up to January 31, 2014. The 3-month, 6-month, and 1-y survivals were calculated from this day. Differences in survival between groups were assessed using the logrank test. Cox proportional hazards regression was used to identify predictors of survival. Multivariate analysis was done using forward-stepwise selection. For the analysis of demographic data and survival, only the first transfer was investigated for each subject. Statistical significance was set at $P=.05$. Statistical analysis was performed using MedCalc 12.7.7 (MedCalc Software bvba, Ostend, Belgium).

\section{Results}

\section{Subject Characteristics}

Sixty-six consecutive subjects were included in the study. Subject data are shown in Table 1 and computed according to the CRF etiology. There was an associated etiology of CRF in 8 of 31 subjects (25.8\%) with lung and airway diseases (rib-cage abnormalities, $n=5$; neuromuscular disease, $n=3$ ); 17 of 25 subjects (68\%) with rib-cage abnormalities (lung and airway diseases, $n=16$; neuromuscular disease, $n=1) ; 3$ of 10 subjects (30\%) with neuromuscular disease (lung and airway diseases, $n=1$; rib-cage abnormalities, $n=2)(P<.001)$. COPD was the primary cause of CRF related to lung or airway disease, affecting $64.5 \%$ of subjects. Tobacco exposure was higher in this group than in other CRF etiology groups.

\section{Subject Care Pathways and Outcomes}

During the follow-up period, 23 of the 66 subjects (34.8\%) were readmitted at least once, so that 109 hospital stays were analyzed. The care pathways are presented in Figure 1. Table 2 shows the resources used, complications, and outcomes related to the 109 hospital stays in our intermediate-care facility. The Charlson score was higher in subjects who were admitted in the intermediate-care facility more than once $(n=23)$ than in subjects who underwent a single admission $(n=43): 5.91 \pm 2.15$ versus $4.87 \pm 1.32(P=.039)$. The pre-intermediate-care facility LOS was shorter when subjects came from our local ICU than when they were admitted from another hospital (median $17 \mathrm{~d}$ vs $60 \mathrm{~d}$, respectively, $P=.001$ ). The median LOS (IQR) was longer in weaned subjects (no ventilation, decannulated, or with maintained tracheostomy tube) than in subjects in whom mechanical ventilation (part-time or full-time) was maintained: 75 (44-105) d versus 36 (21-56) d, respectively $(P=.004)$. During the stay in the intermediate-care facility, 16 subjects $(24 \%)$ died (respiratory exhaustion and/or cachexia, $n=9$; aspiration pneumonia, $n=2$; multi-organ failure, $n=2$; barotrauma, $n=2$; massive hemoptysis, $n=1$ ).
Table 2. Resources Used During the 109 Hospital Stays and Subject Outcomes

\begin{tabular}{|c|c|}
\hline Parameters & Values \\
\hline \multicolumn{2}{|l|}{ Referral source, $n(\%)$} \\
\hline Home & $44(40.4)$ \\
\hline ICU & $44(40.4)$ \\
\hline Another hospital & $21(19.2)$ \\
\hline \multicolumn{2}{|l|}{ Admission diagnosis, $n(\%)$} \\
\hline Weaning & $41(37.6)$ \\
\hline Respiratory failure* & $40(36.7)$ \\
\hline Respite for caregivers & $12(11.0)$ \\
\hline Cachexia & $7(6.4)$ \\
\hline Other & $9(8.3)$ \\
\hline \multicolumn{2}{|l|}{ Pre-ICF LOS, median (IQR) d } \\
\hline Overall & $21(7-56)$ \\
\hline When subject came from ICU & $17(7-38)$ \\
\hline When subject came from another hospital & $60(8-71) \dagger$ \\
\hline ICF LOS, median (IQR) d & $42(26-77)$ \\
\hline \multicolumn{2}{|l|}{ Complications during 109 hospital stays, $n(\%)$} \\
\hline Respiratory sepsis $\ddagger$ & $45(41.3)$ \\
\hline Non-respiratory sepsis§ & $7(6.4)$ \\
\hline Hypercapnic encephalopathy & $2(1.8)$ \\
\hline Pressure ulcers & $2(1.8)$ \\
\hline Hemoptysis & $2(1.8)$ \\
\hline Pneumothorax & $2(1.8)$ \\
\hline Other\| & $3(2.8)$ \\
\hline \multicolumn{2}{|l|}{ Ventilatory outcome, no. hospital stays (\%) } \\
\hline \multicolumn{2}{|l|}{ Weaning after admission in ICF } \\
\hline No ventilator, decannulated & 15I (13.8) \\
\hline No ventilator, tracheostomy maintained & $18(16.5)$ \\
\hline \multicolumn{2}{|l|}{ Ventilator-dependent with tracheostomy } \\
\hline Part-time mechanical ventilation & $61(55.9)$ \\
\hline Full-time mechanical ventilation & $15(13.8)$ \\
\hline \multicolumn{2}{|l|}{ Discharge destination, $n(\%)$} \\
\hline Home & 78 (71.6) \\
\hline ICU & $4(3.7)$ \\
\hline Another hospital & $6(5.5)$ \\
\hline Skilled nursing facility & $5(4.5)$ \\
\hline Death & $16(14.7)$ \\
\hline \multicolumn{2}{|c|}{$\begin{array}{l}\text { * Causes of respiratory failure (not mutually exclusive): acute-on-chronic hypercapnic failure, } \\
n=32 \text {; lower-respiratory-tract infection, } n=14 ; \text { ARDS, } n=7 \text {. } \\
\dagger P=.001 \text { between locations. } \\
¥ \text { Lower-respiratory-tract infection, } n=35 \text {; aspiration pneumonia, } n=7 \text {; empyema, } n=3 \text {. } \\
\S \text { Cheilitis, } n=2 \text {; urinary-tract infection, } n=2 \text { ( } 1 \text { case combined with lower-respiratory-tract } \\
\text { infection); Clostridium difficile infection, } n=2 \text { ( } 1 \text { case combined with lower-respiratory-tract } \\
\text { infection); septic shock, } n=1 \text {. } \\
\| \text { Gastrointestinal hemorrhage, ileus, vertebral fracture. } \\
\text { I } 8 \text { of } 15 \text { decannulated subjects were treated with noninvasive ventilation. } \\
\text { ICF = intermediate-care facility } \\
\text { LOS = length of stay } \\
\text { IQR = interquartile range }\end{array}$} \\
\hline
\end{tabular}

\section{Survival Analysis}

The mean survival of subjects was $589 \mathrm{~d}(95 \%$ CI $476-$ $700 \mathrm{~d}$ ). Mortality rates in hospital survivors were $16 \%$ at 3 months, $26 \%$ at 6 months, and $43 \%$ at $1 \mathrm{y}$. The mean 


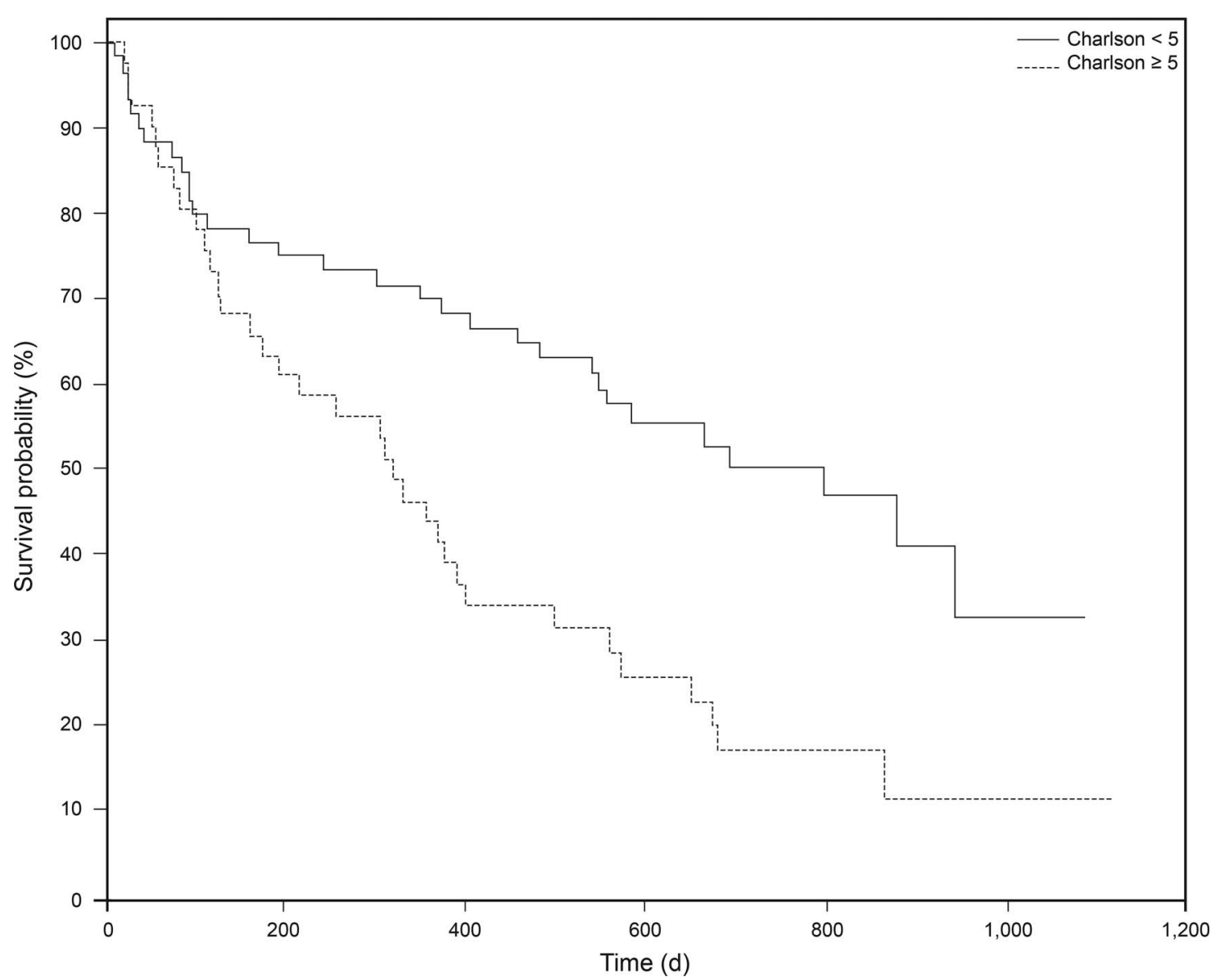

Fig. 2. Kaplan-Meier survival plot of 2 groups of hospital survivors according to Charlson score.

survival was longer in subjects whose Charlson score was $\leq 5$ (mean 724 d, 95\% CI 559-889 d) than in subjects whose Charlson score was $>5$ (median $451 \mathrm{~d}$, 95\% CI 175-400 d). Figure 2 shows the Kaplan-Meier survival curve of the subjects according to this criterion. The following predictors of survival were identified by multivariate analysis: Charlson score $>5$ (negative prognostic factor, relative risk $2.32,95 \%$ CI $1.11-4.85, P=.03$ ) and the main diagnosis of CRF (relative risk $0.51,95 \%$ CI $0.29-$ $0.87, P=.02$ ). According to our classification of CRF, this means that CRF caused by lung or airway diseases (mainly COPD) tended to have a poorer prognosis than CRF caused by neuromuscular diseases or thoracic restrictions. The variables that were not included in the model because of statistical insignificance were age, LOS, subject source, body mass index, sex, and tobacco use $>10$ pack-years.

\section{Discussion}

This study provides insight into an understudied population of critically ill subjects admitted to an intermediate- care facility. A cohort of $66 \mathrm{CRF}$ subjects who received PMV was followed for $2 \mathrm{y}$, and outcomes were satisfactory in terms of 1-y survival and/or weaning from ventilation, at the expense of a high consumption of resources, as shown by the long LOS in our unit and other hospital units before transfer and by the high readmission rate.

Because of continuous progress in acute critical care, the population of patients requiring PMV is growing, resulting in an increased number of patients with ventilatordependent CRF, which has led to the emergence of the concept of respiratory "chronic critical illness." 11 Studying the resources needed by these patients includes recording the LOS in the medical units managing these patients and describing where patients are managed. ${ }^{2,11}$ The median LOS in our unit (42 d) was identical to that observed in a similar cohort of subjects in Olmsted County, Minnesota. ${ }^{13}$ Carson ${ }^{14}$ has also found a similar range of LOS in such units (29-51 d). Like Engoren et al, ${ }^{15}$ we found that decannulated subjects had a longer LOS than subjects discharged with tracheostomy and ventilator-dependent subjects. This may reflect the fact that weaning from mechanical ventilation shifts a patient from a stable to an 
unstable state that requires additional management and monitoring. ${ }^{16}$ The pre-intermediate-care facility LOS of our subjects in previous units differed according to their care pathways, ranging from $17 \mathrm{~d}$ in subjects coming from our local ICU to $60 \mathrm{~d}$ in subjects transferred from another hospital. This finding supports the need for an organized health-care system, aiming to reduce the time elapsed between the request for an intermediate-care facility bed and admission to a step-down unit. Setting up efficient care pathways in these patients is critical, as transfers in care venues are frequent. ${ }^{11}$ Unroe et $\mathrm{al}^{2}$ found that there were 150 readmissions among 68 (66\%, mean of 2.2 readmissions/subject) of the 103 hospital survivors followed in their study. This value is higher than our finding of 66 readmissions among 23 (46\%, mean of 2.9 readmissions/subject) of the 50 hospital survivors. The factors explaining this difference are difficult to identify, as they may be patient- or system-dependent and differ according to the health-care system involved. Rose et al ${ }^{17}$ showed that $34 \%$ of their subjects were transferred back to the referral ICU because of a lack of beds in step-down units. Fortunately, this was not the case in our setting, given that $<4 \%$ of transfers were done from our intermediate-care facility to the ICU.

We acknowledge the fact that the proportion of subjects achieving a successful weaning in our cohort was not as high as in specialized weaning centers. Schönhofer et al ${ }^{18}$ obtained a complete or partial weaning in $68 \%$ of their subjects, but excluded patients who had no chance to be weaned or with end-stage diseases. However, this may not be representative of units managing unselected ventilatordependent patients. Thirty percent of the 109 hospital stays in our intermediate-care facility led to a complete or partial weaning, an intermediate value between the weaning rate of $19 \%$ obtained in Italian respiratory ICUs ${ }^{6}$ and that of $34 \%$ obtained by van der Lely et $\mathrm{al}^{19}$ in subjects with respiratory insufficiency requiring PMV.

Fifty-seven percent of our subjects were alive at $1 \mathrm{y}$, in accordance with the 50 and $52 \%$, respectively, found by Engoren et $\mathrm{al}^{15}$ and Cox et al. ${ }^{9}$ It is likely that the management of these patients has improved: $15 \mathrm{y}$ ago, only $23 \%$ of PMV patients were alive at $1 \mathrm{y} .{ }^{20} \mathrm{We}$ also found, like Kojicic et al, ${ }^{13}$ that the comorbidities assessed using the Charlson score were inversely correlated with the 1-y survival (data not shown). Like Unroe et $a l,{ }^{2}$ we found that comorbidities may be associated with a higher readmission rate.

Our study has several limitations. First, this was a retrospective study, with all of the methodological issues associated with this type of design for data evaluation. Second, subject data were recorded in a single institution, so that the comparison between values reported for different care settings in subjects with PMV is complicated by differences in case-mix and illness severity. As stated by Elliott, ${ }^{21}$ ICUs, high dependence units, ${ }^{6}$ general wards, and intermediate-care facilities have different levels of staffing and facilities from one country to another. Finally, we did not evaluate the functional status and quality of life of subjects, whereas these factors have been shown to be severely impaired in subjects undergoing PMV. ${ }^{9}$

\section{Conclusions}

The incidence of chronically ill patients with PMV is increasing because of improvements in acute critical care. ${ }^{14}$ Our study shows that following acute-care hospital stays, satisfactory outcomes may be obtained in intermediatecare facilities dedicated to the management of subjects with PMV. Indeed, $57 \%$ of our cohort was alive at $1 \mathrm{y}$, and $>70 \%$ of subjects were discharged home. However, the resources needed by these patients are high, as shown by the long LOS in our unit and other units before transfer, the high readmission rate, and the impact of the comorbidities on the long-term prognosis.

\section{ACKNOWLEDGMENTS}

I thank François Viau MD, Christian Darné MD, Françoise Haniez MD, and Hélène Jaillet MD for assistance with data collection.

\section{REFERENCES}

1. Make BJ, Hill NS, Goldberg AI, Bach JR, Criner GJ, Dunne PE, et al. Mechanical ventilation beyond the intensive care unit: report of a consensus conference of the American College of Chest Physicians. Chest 1998;113(5 Suppl):289S-344S.

2. Unroe M, Kahn JM, Carson SS, Govert JA, Martinu T, Sathy SJ, et al. One-year trajectories of care and resource utilization for recipients of prolonged mechanical ventilation: a cohort study. Ann Intern Med 2010;153(3):167-175.

3. Durbin CG Jr. Tracheostomy: why, when, and how? Respir Care 2010;55(8):1056-1068.

4. Corrado A, Roussos C, Ambrosino N, Confalonieri M, Cuvelier A, Elliott M, et al. Respiratory intermediate care units: a European survey. Eur Respir J 2002;20(5):1343-1350.

5. Scheinhorn DJ, Hassenpflug MS, Votto JJ, Chao DC, Epstein SK, Doig GS, et al. Post-ICU mechanical ventilation at 23 long-term care hospitals: a multicenter outcomes study. Chest 2007;131(1):85-93.

6. Scala R, Corrado A, Confalonieri M, Marchese S, Ambrosino N, Scientific Group on Respiratory Intensive Care of the Italian Association of Hospital Pneumologists. Increased number and expertise of Italian respiratory high-dependency care units: the second national survey. Respir Care 2011;56(8):1100-1107.

7. Ceriana P, Delmastro M, Rampulla C, Nava S. Demographics and clinical outcomes of patients admitted to a respiratory intensive care unit located in a rehabilitation center. Respir Care 2003;48(7):670-676.

8. Scheinhorn DJ, Hassenpflug MS, Votto JJ, Chao DC, Epstein SK, Doig GS, et al. Ventilator-dependent survivors of catastrophic illness transferred to 23 long-term care hospitals for weaning from prolonged mechanical ventilation. Chest 2007;131(1):76-84.

9. Cox CE, Martinu T, Sathy SJ, Clay AS, Chia J, Gray AL, et al. Expectations and outcomes of prolonged mechanical ventilation. Crit Care Med 2009;37(11):2888-2894. 


\section{INTERMEDIATE-CARE FACILITY FOR PMV}

10. Travers N, Viau F, Darne C, Canh VN, Andrivet P. Difficult weaning: ten year experience of the Bligny Medical Center. Réanimation 2004;13(1):79-87.

11. Donahoe MP. Current venues of care and related costs for the chronically critically ill. Respir Care 2012;57(6):867-886; discussion 886-888.

12. Lloyd-Owen SJ, Donaldson GC, Ambrosino N, Escarabill J, Farre R, Fauroux B, et al. Patterns of home mechanical ventilation use in Europe: results from the Eurovent survey. Eur Respir J 2005; 25(6):1025-1031.

13. Kojicic M, Li G, Ahmed A, Thakur L, Trillo-Alvarez C, Cartin-Ceba $\mathrm{R}$, et al. Long-term survival in patients with tracheostomy and prolonged mechanical ventilation in Olmsted County, Minnesota. Respir Care 2011;56(11):1765-1770.

14. Carson SS. Definitions and epidemiology of the chronically critically ill. Respir Care 2012;57(6):848-856; discussion 856-858.

15. Engoren M, Arslanian-Engoren C, Fenn-Buderer N. Hospital and long-term outcome after tracheostomy for respiratory failure. Chest 2004;125(1):220-227.
16. Scheinhorn DJ, Hassenpflug M, Artinian BM, LaBree L, Catlin JL. Predictors of weaning after 6 weeks of mechanical ventilation. Chest 1995;107(2):500-505.

17. Rose L, Fraser IM. Patient characteristics and outcomes of a provincial prolonged-ventilation weaning centre: a retrospective cohort study. Can Respir J 2012;19(3):216-220.

18. Schönhofer B, Euteneuer S, Nava S, Suchi S, Köhler D. Survival of mechanically ventilated patients admitted to a specialised weaning centre. Intensive Care Med 2002;28(7):908-916.

19. van der Lely AJ, Veelo DP, Dongelmans DA, Korevaar JC, Vroom MB, Schultz MJ. Time to wean after tracheotomy differs among subgroups of critically ill patients: retrospective analysis in a mixed medical/surgical intensive care unit. Respir Care 2006; 51(12):1408-1415.

20. Carson SS, Bach PB, Brzozowski L, Leff A. Outcomes after longterm acute care: an analysis of 133 mechanically ventilated patients. Am J Respir Crit Care Med 1999;159(5 Pt 1):1568-1573.

21. Elliott MW, Confalonieri M, Nava S. Where to perform noninvasive ventilation? Eur Respir J 2002;19(6):1159-1166.

This article is approved for Continuing Respiratory Care Education credit. For information and to obtain your CRCE

(free to AARC members) visit

www.rcjournal.com 